\title{
Catchment classification based on characterisation of streamflow and precipitation time series
}

\author{
E. Toth \\ Department DICAM, University of Bologna, Bologna, Italy \\ Correspondence to: E. Toth (elena.toth@unibo.it) \\ Received: 24 August 2012 - Published in Hydrol. Earth Syst. Sci. Discuss.: 26 September 2012 \\ Revised: 5 February 2013 - Accepted: 25 February 2013 - Published: 15 March 2013
}

\begin{abstract}
The formulation of objective procedures for the delineation of homogeneous groups of catchments is a fundamental issue in both operational and research hydrology. For assessing catchment similarity, a variety of hydrological information may be considered; in this paper, gauged sites are characterised by a set of streamflow signatures that include a representation, albeit simplified, of the properties of fine time-scale flow series and in particular of the dynamic components of the data, in order to keep into account the sequential order and the stochastic nature of the streamflow process.

The streamflow signatures are provided in input to a clustering algorithm based on unsupervised SOM neural networks, obtaining groups of catchments with a clear hydrological distinctiveness, as highlighted by the identification of the main patterns of the input variables in the different classes and the interpretation of their interrelations. In addition, even if no geographical, morphological nor climatological information is provided in input to the SOM network, the clusters exhibit an overall consistency as far as location, altitude and precipitation regime are concerned.

In order to assign ungauged sites to such groups, the catchments are represented through a parsimonious set of morphometric and pluviometric variables, including also indexes that attempt to synthesise the variability and correlation properties of the precipitation time series, thus providing information on the type of weather forcing that is specific to each basin. Following a principal components analysis, needed for synthesizing and better understanding the morpho-pluviometric catchment properties, a discriminant analysis finally assigns the ungauged catchments, through a leave-one-out cross validation, to one of the above identified hydrologic response classes. The approach delivers a
\end{abstract}

quite satisfactory identification of the membership of ungauged catchments to the streamflow-based classes, since the comparison of the two cluster sets shows a misclassification rate of around $20 \%$.

Overall results indicate that the inclusion of information on the properties of the fine time-scale streamflow and rainfall time series may be a promising way for better representing the hydrologic and climatic character of the study catchments.

\section{Introduction}

The identification of groups of hydrologically similar catchments is a fundamental issue in both operational and research hydrology: it is essential to ensure the transferability of information when applying regionalisation methods, but can also provide valuable indications to improve the understanding of the dominant physical phenomena in the different groups (McDonnell and Woods, 2004; Wagener et al., 2007; Sawicz et al., 2011). The similarity may be evaluated in terms of signatures of catchments' functional responses, quantifying the characteristics of the hydrologic response that provide insight into the behaviour of the catchment (Atkinson et al., 2002; Wagener et al., 2007; Yilmaz et al., 2008; Oudin et al., 2010). A comprehensive set of measures describing all aspects of the catchment hydrology (such as meteorological observations, soil moisture content, vegetation patterns, etc.) should in principle be analyzed in order to fully understand these functional characteristics, but unfortunately such measures are not available in the majority of catchments. It is therefore worthy analyzing the information content embedded in data far more generally available, such as streamflow measures, even if acknowledging that in this way, 
while it is possible to include in the study a much greater number of catchments, the similarity analysis can provide only a first-order classification (Wagener et al., 2007; Sawicz et al., 2011). On the other hand, streamflow may be seen as an integrator of all climatic and morphologic conditions of a given basin (Samaniego et al., 2010), thus justifying such an empirical approach. To this end, a variety of indexes based on streamflow measurements may be adopted, characterizing in a different way the hydrological response of the basin, generally depending on the type of analysis to be carried out. The most frequent and compelling need for the assessment of regional similarity in catchment response is in fact for issuing predictions in ungauged catchments, and the choice of the streamflow indexes to be compared depends on the finality of the regional analysis, that is on the variable to be predicted.

The large majority of regionalisation studies performing an objective catchment classification, through the use of clustering techniques, has concerned, since the $80 \mathrm{~s}$, flood frequency analysis (e.g. Hosking et al., 1985; Lettenmaier et al., 1987; Burn, 1989; Burn et al., 1997; Burn and Goel, 2000; Castellarin et al., 2001; Merz and Bloeschl, 2005). For such analyses, the main representative streamflow variables are, naturally, the flood peaks values. If the objective is, instead, the assessment of water availability, the streamflow indexes to be predicted may be for example mean annual or monthly flows (e.g. Haines et al., 1988; Holmes et al., 1999; Viglione et al., 2006) or low flow percentiles (e.g. Nathan and McMahon, 1990; Laaha and Bloeschl, 2006; Vezza et al., 2010) or the entire flow duration curve (e.g. Singh et al., 2001; Ley et al., 2011; Patil and Stieglitz, 2011; Sauquet and Catalogne, 2011). On the other hand, such representations do not allow to take into account the sequential order and the stochastic nature of the streamflow process; these properties would, for example, be crucial if the regionalisation aimed, as often needed in the hydrological practice, at the parameterisation of a rainfall-runoff model at fine temporal scale and the catchment similarity should therefore be guaranteed in terms of continuous streamflow generation.

It may therefore be important also representing and comparing, in addition to mean values or percentiles, the properties of the low time-scale streamflow series and in particular the dynamic components of the data. Information on the effect of complex driving factors on the hydrological response (not always easy to recognise) are in fact embedded in the temporal dynamics of the streamflow series (Chiang et al., 2002; Corduas, 2011). Important differences among the streamflow processes may be highlighted by the analysis of their temporal correlation structure, representable through the global autocorrelation function ACF (or the corresponding power spectrum). Since the time series autocorrelation functions might differ strongly one from another in shape, their comparison and classification through a visual inspection or a synthesising index is not straightforward. To tackle this issue, recent studies (De Thomasis and Grimaldi, 2001;
Chiang et al., 2002; Grimaldi, 2004; Corduas, 2011) proposed to analyze the streamflow temporal dynamics through the parameter sets of linear models estimated on the corresponding streamflow time series. A more parsimonious, but less refined and necessarily approximated, approach is applied here for representing the autocorrelation structure: in addition to the lag-1 autocorrelation coefficient (previously used in regionalisation studies, for example, by Montanari and Toth (2007); Castiglioni et al. (2010); Lombardi et al. (2012) for the parameterisation of a rainfall-runoff model), it is here proposed to use an index representing the shape of the ACF, i.e. the correlation scaling exponent. Such index has been used for analysing the scale properties of meteorological and hydrological data (see, e.g., Menabde et al., 1997; Marani, 2003; Molnar and Burlando, 2008; Ozger et al., 2012), but never, so far, for catchment classification purposes.

Section 2 presents the study area and the indexes estimated for both gauged and ungauged catchments; in Sect. 3, the set of descriptors summarising the main statistical features of the streamflow time series (including the coefficients above cited for representing the temporal correlation structure) are provided in input to a clustering algorithm based on unsupervised SOM neural networks, recently proposed for catchment classification, but so far never utilised for classifying attributes based on time series properties.

The final aim of the study is the assignment of ungauged catchments to the classes obtained from the similarity of the river flow time series, presented in Sect. 4. To this end, the ungauged catchments are characterised through a set of indexes describing their morphology and the main rainfall properties. In particular, besides the morphological indices, it was deemed appropriate to rely on the information content of long, high-resolution rainfall time series, given the importance of such information for understanding the prevailing patterns in discharge time series (see, e.g., Thomas et al., 2012). In analogy with the streamflow series representation, the rainfall attributes include also the indexes describing the temporal variability of the series, that allow to incorporate information on the dynamics of the process, thus characterizing the type of weather forcing that is specific to each basin. The present paper provides the first ever catchment classification to be performed including coefficients (and in particular the correlation scaling exponent) characterising the fine timescale variability and correlation structure of both streamflow and rainfall fine-resolution time series. Following a principal components analysis (Sect. 4.1), needed for synthesising and better understanding the morpho-pluviometric catchment properties, a discriminant analysis (Sect. 4.2) is then applied in a leave-one-out cross validation approach, to identify the membership of ungauged catchments to the original hydrometric classes. It is therefore finally possible to determine the error rate for classifying the streamflow properties based on catchment descriptors that are available also in absence of hydrometric measurements. 


\section{Study area and classification attributes}

\subsection{Study area and data}

The study region includes 44 catchments, spanning the northeastern side of the Apennine mountains and piedmont area (Emilia-Romagna), in Italy. The Apennines of north-central Italy are a fold-and-thrust mountain chain related to an orogenic system (chain-foredeep-foreland), derived from the post-Eocene collisional history between the European and African plates and from a complex, multi-staged evolution. The topographic relief is made up of a series of ridges elongated in directions that vary from S-N to SW-NE, separated one from the other by narrow valleys or by wide intermontane tectonic depressions (Piacentini et al., 2011). The landscape is rougher and steeper in the western chain, whereas the Adriatic piedmont areas are characterised mostly by gently reliefs down to the coastal lowlands.

The south-eastern part of the region (named Romagna) is actually a different hydrographic region, since it is formed by rivers flowing directly in the Adriatic Sea, while the remaining catchments are all headwater tributaries to the Po River (the most important Italian river), belonging to the western part of the region (Emilia). Also the climate varies between the two areas from mountainous to maritime, going from the higher crests of the western side to the eastern coastal and hilly area. The western side of the region experiences more rain, with annual rainfall depths that exceed $2000 \mathrm{~mm}$ in the mountains, whereas the climate in the Romagna area changes due to the wind exposition, to the influence of the sea, to the lower orography and also to the lower latitude. Figure 1 shows mean annual precipitation depths and elevation of the Emilia-Romagna Region.

For each of the study catchments, time series data of hourly streamflow were collected for a total number of observations ranging, for the different river sections, from 31519 to 85469 (that would correspond respectively to more than 3.5 and almost $10 \mathrm{yr}$ of continuous monitoring but, as a matter of fact, embrace periods of missing data). Hourly streamflow data are expressed as spatial averaged runoff depths $\left(\mathrm{mm} \mathrm{h}^{-1}\right)$. Areal precipitation estimates, again at hourly step $\left(\mathrm{mm} \mathrm{h}^{-1}\right)$, were interpolated with Thiessen-polygon weighting from nearby rain-gauges.

\subsection{Streamflow signatures}

The first step of the proposed approach is to cluster the catchments on the basis of the hydrologic response, as defined by key signatures of the streamflow time series. The chosen signatures are (i) average runoff, $\mu_{Q}$, (ii) the standard deviation, $\sigma_{Q}$, and (iii-iv) the 5 th and 95 th percentiles, $P_{Q, 5}$ and $P_{Q, 95}$ of hourly data. To describe the correlation structure of the series, representing the dynamic component of the process, two metrics were computed: (v) the lag-1 autocorrelation coefficient, $\rho_{Q}(1)$, and (vi) the correlation scaling
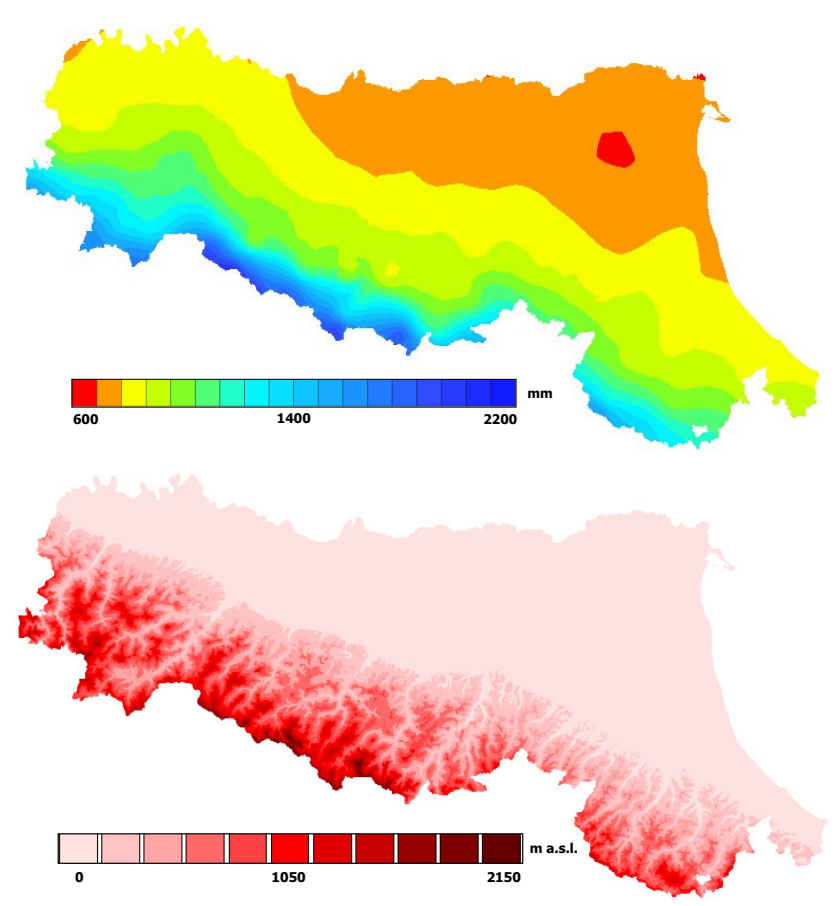

Fig. 1. Mean annual precipitation ("Precipitazioni annue - Periodo 1991-2008”, ARPA Regione Emilia Romagna) and digital elevation model of the Emilia-Romagna region.

exponent (see for example Menabde et al., 1997, and Molnar and Burlando, 2008, for precipitation data, and the recent application by Ozger et al., 2012, to streamflow time series), that is the exponent that characterises the correlation function with a power law:

$\rho_{Q}(\tau) \propto \tau^{-\alpha}$,

where $\rho_{Q}$ is the autocorrelation function, $\tau$ is the time lag, and $\alpha_{Q}$ is the correlation scaling exponent. Values of $\alpha_{Q}$ tending to 0 indicate strongly correlated data, values close or higher than 1 show absence of correlation. Actually, the analysis of the correlation structures would require stationary time series, whereas streamflow observations (as well as rainfall ones) exhibit a strong dependency on the season (see also the recent analysis by Patil and Stieglitz, 2011); to solve this problem, the above cited papers assume stationarity on a seasonal basis, estimating separate coefficients for the different seasons or months. In addition, if trends were present, Eq. (1) may not be capable of characterizing the structure of data in terms of multifractality and correlation dimension (see, e.g. Ozger et al., 2012). Nonetheless, due to the limited number of catchments in the data set, it was deemed appropriate, in this first study, to retain the smallest possible number of streamflow signatures, in order to avoid over-parameterisation effects in the classification technique; for this reason, even if acknowledging the strong limitations of this approximation, stationarity was hypothesised and only one value for $\alpha_{Q}$ was estimated for each time series. 


\subsection{Catchment descriptors}

In order to extend the analysis of the hydrological similarity also to catchments devoid of flow measurements, indexes describing the basins from the geo-morphological and climatological point of view are identified. The main geographical and morphometric attributes are derived from digital catchment boundaries coupled with the digital elevation model: (i)-(ii) the geographical coordinates UTM $X$ and $Y$ of the stream gauges; (iii) drainage area, $A$, (iv)-(v) minimum and average catchment elevation, $H_{\min }$ and $H_{\text {med }}$, and (vi) main stream length, $L$. In addition, to better describe the catchments as far as the rainfall-runoff transformation is concerned, indexes obtained from the high-resolution areal rainfall time series are estimated, thus attempting to characterise the fine time-scale variability and correlation structure of the precipitation process. The chosen pluviometric attributes are (i)-(ii) the mean and the standard deviation of the hourly data, $\mu_{P}$ and $\sigma_{P}$; (iii) the average proportion of wet hours (hours with more than $0.2 \mathrm{~mm}$ of rain), $P_{\text {Wet }}$; finally, in analogy with the streamflow signatures, (iv) the lag-1 autocorrelation coefficient, $\rho_{P}(1)$, and (v) the correlation scaling exponent, $\alpha_{P}$, of the precipitation time series are computed.

The chosen streamflow signatures and catchment attributes (pluviometric and morphometric) are listed in Table 1 , along with the corresponding observation ranges over the data-set.

\section{Classification of streamflow signatures with SOM neural networks}

In the past three decades a number of applications of cluster analysis techniques have been presented in the hydrologic literature for the objective identification of catchments having similar attributes (either geographic, morphometric, climatic and/or based on streamflow observations). In the recent years, also non-supervised neural networks, and in particular of the SOM (self-organising mapping) type, were successfully applied (and sometimes compared with other methods such as K-means or Fuzzy C-means) for catchments classification purposes (Hall and Minns, 1999; Hall et al., 2002; Jingyi and Hall, 2004; Chang et al., 2008; Srinivas et al., 2008; Di Prinzio et al., 2011; Ley et al., 2011). SOM-type neural networks learn to cluster the input data by recognizing different patterns organising the data on the basis of their similarity, quantified by means of a distance measure (in the present case, like in the majority of applications, the Euclidean distance). More details on the SOMs and in particular on their use as classification techniques may be found for example in Herbst and Casper (2008) or in Toth (2009). The networks are formed by two layers of interconnected nodes (or neurons): each attribute of the entity to be classified (i.e. a catchment) is fed to one of the input nodes, while the output nodes correspond to the classes to which the entities are assigned. An input vector $\boldsymbol{x}=\left(x_{1}, x_{2}, \ldots, x_{n}\right)$ activates in fact only one output node, representing its class, using the Kohonen competitive learning rule (Kohonen, 1997). Each output node is characterised by the weights connecting it to the input nodes. Initially the weights between the $n$ input nodes and each output node are randomly assigned. When, in the training phase, an input is sent through the network, each output neuron computes the distance between its weights $\boldsymbol{W}=\left(w_{1}, w_{2}, \ldots, w_{n}\right)$ and the input vector:

$\|\boldsymbol{x}-\boldsymbol{W}\|=\sqrt{\sum_{i=1}^{n}\left(x_{i}-w_{i}\right)^{2} .}$

The output node responding maximally to the given input vector - specifically, the weights vector having the minimum distance from the input vector - is the winning neuron. At each training iteration $t$, the weights of the winning node and of its neighbouring nodes change, so to further reduce the distance between the weights and the input vector:

$\boldsymbol{W}(t+1)=\boldsymbol{W}(t)+\mu(t) h_{l m}(\boldsymbol{x}-\boldsymbol{W}(t))$,

where $\mu$ is the learning rate, $\in[01], \boldsymbol{l}$ and $\boldsymbol{m}$ are the positions of the winning and its neighbouring output nodes and $h_{l m}$ is the neighbourhood shape, that reduces the adjustment for increasing distance, namely,

$h_{l m}=\exp \left(-\frac{\|\boldsymbol{l}-\boldsymbol{m}\|^{2}}{2 \theta(t)^{2}}\right)$,

where $\|\boldsymbol{l}-\boldsymbol{m}\|$ is the lateral distance between $\boldsymbol{l}$ and $\boldsymbol{m}$ on the output grid and $\theta$ is the width of the topological neighbourhood.

Lateral interaction between neighbouring output nodes ensures that learning is a topology-preserving process in which the network adapts to respond in different locations of the output layer for inputs that differ, while similar input patterns activate adjacent output units, corresponding to akin classes, as will be shown in the next subsections.

The values of the streamflow signatures (i.e. the input vectors) are standardized to zero mean and unit variance, so to give them equal importance in the evaluation of the distance measure.

The number of input variables (six in the present case) corresponds to the dimension of the input layer, whereas the dimension of the output layer is equal to the number of classes to be determined.

\subsection{SOM classification in 6 clusters}

There is no principled definitive statistical method for choosing the most appropriate number of partitions in a data set, and such choice mainly depends on the clustering resolution desired by the user. 
Table 1. Streamflow signatures, pluviometric and morphometric attributes.

\begin{tabular}{lll}
\hline Streamflow signatures & & Observations Range \\
\hline Average runoff & $\mu_{Q}\left(\mathrm{~mm} \mathrm{~h}^{-1}\right)$ & $0.013-0.233$ \\
Standard deviation runoff & $\sigma_{Q}\left(\mathrm{~mm} \mathrm{~h}^{-1}\right)$ & $0.036-0.588$ \\
Percentile 95\% runoff & $P_{Q, 95}\left(\mathrm{~mm} \mathrm{~h}^{-1}\right)$ & $0.035-0.767$ \\
Percentile 5\% runoff & $P_{Q, 5}\left(\mathrm{~mm} \mathrm{~h}^{-1}\right)$ & $0.000-0.021$ \\
Lag-1 autocorrelation runoff & $\rho_{Q}(1)$ & $0.962-0.998$ \\
Correlation scaling exponent runoff & $\alpha_{Q}$ & $0.088-0.474$ \\
\hline Pluviometric attributes & & Observations Range \\
\hline Average precipitation & $\mu_{P}\left(\mathrm{~mm} \mathrm{~h}^{-1}\right)$ & $0.084-0.258$ \\
Standard deviation precipitation & $\sigma_{P}\left(\mathrm{~mm} \mathrm{~h}^{-1}\right)$ & $0.480-1.309$ \\
Proportion of wet hours & $P_{\mathrm{Wet}}$ & $0.065-0.122$ \\
Lag-1 autocorrelation precipitation & $\rho_{P}(1)$ & $0.517-0.826$ \\
Correlation scaling exponent precipitation & $\alpha_{P}$ & $0.715-1.071$ \\
\hline Morphometric attributes & & Observations Range \\
\hline Coordinate $X$ UTM stream gauge & $X(\mathrm{~m})$ & $525736-758845$ \\
Coordinate $Y$ UTM stream gauge & $Y(\mathrm{~m})$ & $4869659-4982633$ \\
Drainage area & $A\left(\mathrm{~km}{ }^{2}\right)$ & $18-1303$ \\
Minimum catchment elevation & $H_{\mathrm{min}}(\mathrm{m}$ a.s.1.) & $8-896$ \\
Average catchment elevation & $H_{\mathrm{med}}(\mathrm{m}$ a.s.l. $)$ & $308-1411$ \\
Main stream length & $L(\mathrm{~km})$ & $3-93$ \\
\hline & & \\
\hline
\end{tabular}

In the present work, a first SOM application partitions the streamflow attributes vectors into six classes, i.e. in a relatively large (in reference to the number of entities to be classified) number of groups, aiming at a sufficiently detailed discrimination between the classes, so to highlight the most important features of the data drawn from the input space. The SOM may in fact be seen also as an information content extractor, projecting the analysed entities (streamflow signatures vectors) on the output layer, which has a lower dimension (2-dim) than that of the inputs (6-dim). The SOM output layer is set equal to $3 \times 2$ nodes, corresponding to 6 clusters of similar catchments organised on a hexagonal lattice, so that diagonal neighbours have the same distance as horizontal and vertical ones.

When the training is complete, each vector of streamflow signatures is assigned to its winning node, that corresponds to the class. Figure 2 shows the closure sections of the catchments associated to the six obtained clusters, along with a representation of the hexagonal output layer.

Following the presentation methodology proposed in Chang et al. (2010), a topology map is presented in Fig. 3. Such a map shows the mean value of each streamflow attribute (standardised to zero mean and unit variance) for the catchments of each cluster.

The topology, that is the relative location of the nodes, allows to visualise the variation of the streamflow features along the different classes, characterising the behaviour of the input variables and their interrelations. Class A (top-left hand corner) corresponds to the catchments with the maximum runoff, having the highest values of $\mu_{Q}, \sigma_{Q}, P_{Q, 5}$ and
$P_{Q, 95}$. The adjacent cluster $\mathrm{B}$ retains values of $P_{Q, 5}$ and $P_{Q, 95}$ higher than the regional average (even if to a lesser extent than Class A), whereas $\mu_{Q}$ and $\sigma_{Q}$ are very close to the mean (zero) value. In Class $\mathrm{C}$, which is adjacent to both $\mathrm{A}$ and $\mathrm{B}$, but also to the remaining three classes, all the streamflow signatures are squeezed close to the mean values. On the other hand (and on the opposite part of the lattice), groups D, $\mathrm{E}$ and especially $\mathrm{F}$ (the furthest from the most humid cluster A) correspond to the catchments with the lowest runoff, with negative standardised values of $\mu_{Q}, \sigma_{Q}, P_{Q, 5}$ and $P_{Q, 95}$.

When considering the indexes devised for representing the dynamic component of the process, we can identify the most highly correlated streamflows (large $\rho_{Q}(1)$ and small $\alpha_{Q}$ ), on the top-right hand side (Classes B and D), whereas the less temporally correlated ones (very low values of $\rho_{Q}(1)$ and high $\alpha_{Q}$ ) characterise Class $\mathrm{E}$, on the opposite corner. Classes A and C (top-left corner) have $\rho_{Q}(1)$ and $\alpha_{Q}$ close to the regional mean and the bottom right-hand corner $(F)$ lies in between its neighbours $\mathrm{E}$ and $\mathrm{D}$, with positive (standardised) values for both $\alpha_{Q}$ and $\rho_{Q}(1)$.

The topology map evidences the core morphological and climatological features of the different groups of catchments, as may be inferred from their geographical location, comparing Fig. 2 with Fig. 1: the top-left hand class A (black diamonds) is formed by very rainy but small (due to the reduced size, the streamflow is not strongly correlated) catchments: they are located in the mountainous (southern) part of the western area.

The elements in class B (top but right hand side, white diamonds) have high runoff (but less than those in A) and 


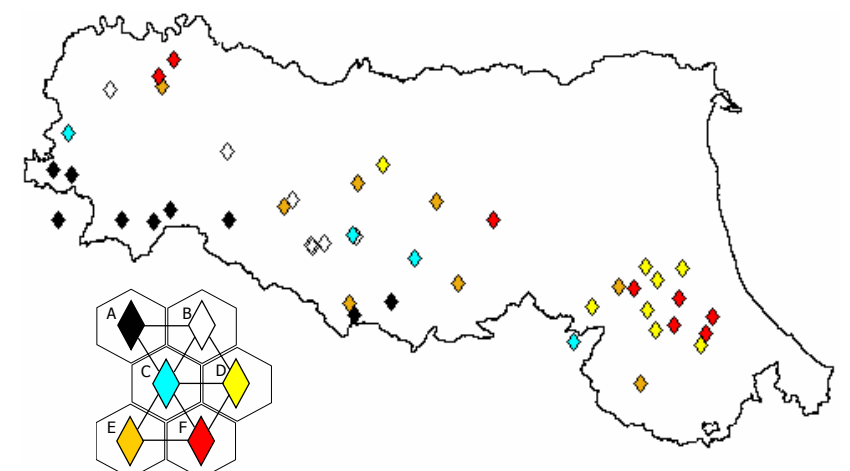

Fig. 2. Catchments of the 6-cluster classification identified by SOM based on streamflow signatures.

show a significant temporal correlation: they are located in the western (more rainy) region too, but more downstream, and have larger areas, so that both the humid climate and the size induce a significant correlation.

Classes F and D (bottom right-hand side) correspond to the less humid catchments: to the first class belong those - from east to west - at lower altitudes (see the position of the red diamonds, in the piedmont or flat part of the region), where the impact of orographic precipitation is limited; the elements of D (yellow) are instead almost all located in the eastern, climatologically less rainy, part of the region (Romagna).

Cluster E (orange) is formed by small basins (the size is consistent on the lattice topology, since the nodes on the left side, $\mathrm{A}$ and $\mathrm{E}$, correspond to the smallest catchments) with modest runoff, characterised by the lowest temporal correlation.

Lastly, class $\mathrm{C}$ is the less markedly characterised, with all streamflow indexes close to the regional averages, as topologically consistent with its position on the lattice, being the neuron that is at equal distance from all the other five. Such more "amorphous" catchments are a minority, four in total, whereas the other groups are formed by 7 to 9 elements, highlighting a good balance in the numerousness of the classes.

\subsection{SOM classification in 3 clusters}

A second SOM application was set up for partitioning the watersheds in three, instead of six, classes. In fact the discriminant analysis to be performed in the second part of the study - aimed at assigning ungauged catchments to the classes identified as a function of the streamflow signatures - needs a less detailed clustering resolution, in order to avoid the effects of overparameterisation. In detail, the number of discriminant variables multiplied by the number of classes should be not greater than one fourth of the total number of records (Hand, 1997; Sanborn and Bledsoe, 2006).

It was hence decided, in this second classification experiment, to limit to three the number of hydrologically

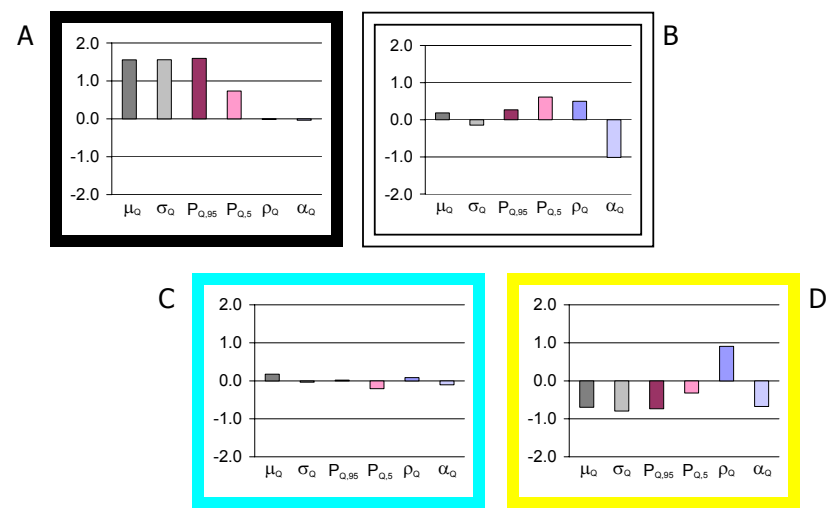

E
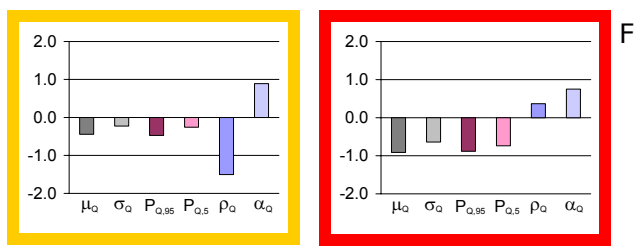

Fig. 3. Topology map of 6 -cluster $(3 \times 2)$ SOM classification of streamflow signature vectors.

homogeneous clusters, with an output layer consisting of only 3 nodes.

Figure 4 indicates the closure sections of the catchments associated to each of the three classes, whereas the topology map (Fig. 5) shows the mean value - for each cluster - of the standardised streamflow attributes.

The trained network associates to Class 1 (magenta) almost half of the study catchments ( 21 over 44 ) formed by the previous (6-cluster) adjacent classes $\mathrm{F}$ and $\mathrm{D}$, plus the majority of class $\mathrm{E}$ (contiguous to $\mathrm{F}$ ). Consistently with the more refined partitioning, such catchments are those that generate the lowest runoff (small values of $\mu_{Q}, P_{Q, 5}, P_{Q, 95}$ and $\sigma_{Q}$, as illustrated in the topology map).

It may be observed in Fig. 4 that Class 1 includes almost all the basins of the south-eastern part of the study area (Romagna) and other lower-altitude and drier catchments located in the downstream (northern) part of the western valleys. It is realistic that the Romagna catchments - that are close to each other and belong, as said in Sect. 2.1, to a distinct hydrographic region - seem to behave in a hydrologically similar way according to this second, coarser classification. In fact such a contiguous area is certainly characterised by similar climate, topography and geology, and all other characteristics deriving from them, such as soil type, vegetation, etc. (Merz and Bloeschl, 2005; Patil et al., 2012).

On the other hand it is evident, as expectable, that the coarser clustering is not able to fully capture the differences among the hydrometric signatures, and in particular among the dynamic components of the streamflow process. Class 1 in fact is characterised, on average, by series that are slightly less autocorrelated than the regional averages (smaller $\rho_{Q}(1)$ and greater $\alpha_{Q}$ ), but it merges basins characterised by very 


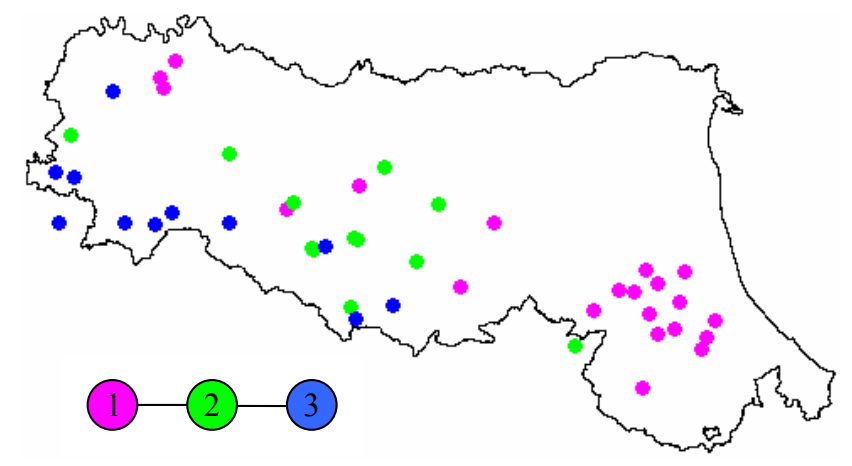

Fig. 4. Catchments of the 3-cluster classification identified by SOM based on streamflow signatures.

different temporal correlation indexes: the less correlated ones (belonging to Class $\mathrm{E}$ of the 6-cluster grouping) along with time series that are instead more correlated (Class D) or characterised by a mixed condition (Class F, having both $\rho_{Q}(1)$ and $\alpha_{Q}$ values above the regional averages). As a consequence, the autocorrelation coefficient and the correlation scaling exponent have limited discriminant power in the 3cluster analysis.

Class 3 (11 elements) incorporates the 6-cluster Class A and a part of Class B, corresponding to the highest runoff (as evidenced by the topology maps) and to a temporal correlation which is, on average, slightly higher than the regional means. Consistently with the geographical location of the elements of Class A (and Class B), Class 3 mainly includes the mountainous catchments of the western area, characterised by higher altitude and precipitation.

Finally, Class 2 (12 catchments) stands in between the other two clusters, adding to the "amorphous" Class $\mathrm{C}$ the catchments of Class E that fit less in the new 3-cluster Class 1 and a few from Classes B and D that do not fit in Class 3 .

Comparing the results of the two classifications (6-cluster and 3-cluster), it is demonstrated that the topological order of the SOM structure guarantees that solutions with more clusters are correctly nested within the solutions that have fewer clusters. On the other hand, the coarser classification is mainly led by the signatures representing runoff magnitude and, while it clearly separates the higher and lower values of $\mu_{Q}, P_{Q, 5}, P_{Q, 95}$ and $\sigma_{Q}$, those of $\rho_{Q}(1)$ and $\alpha_{Q}$ are, instead, extremely variable inside each class, indicating that the dynamic component of the process is not given sufficient consideration.

Despite the above mentioned limitation, the SOM classifications (both 3-cluster and 6-cluster) based on streamflow signatures seem overall to indicate a good grouping ability, as highlighted by the consistent interpretation of how the main features of the input variables vary in the different classes and of their interrelations, as illustrated through the analysis of their topology maps. In addition, even if no geographical, morphological nor climatological information

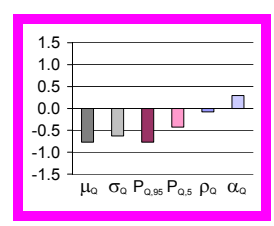

1

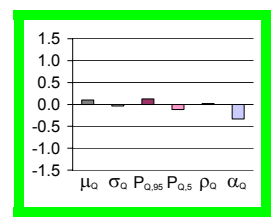

2

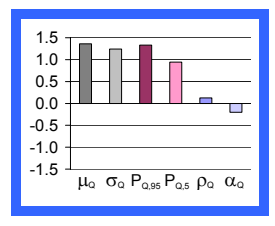

3
Fig. 5. Topology map of 3-cluster SOM classification of streamflow signatures vectors.

is provided in input to the SOM network, the clusters exhibit an overall consistency as far as location, altitude and precipitation regime are concerned.

\section{Application to ungauged catchments}

One of the primary practical objectives for delineating hydrological homogeneous regions is to assess the membership of ungauged sites, thus inferring indications on the response behaviour of such catchments. An important feature of a cluster analysis aimed at identifying homogeneous clusters is therefore the ability to discriminate between them on the basis of variables that are different from the streamflow signatures, namely, a set of physical and climatic characteristics of the watersheds. In Sect. 3, the SOM was applied as an unsupervised methodology for grouping together catchments that are similar from the hydrometric point of view. The objective of the methodology presented in this section is to assign to such classes any new watershed where the streamflow attributes are not available. A discriminant analysis is applied as a supervised learning technique, that assigns each record to predefined groups. To this end, it constructs a classification rule based on the knowledge, for the same catchments, of (i) the morphologic and pluviometric properties presented in Sect. 2.3 (chosen as discriminant) and (ii) the hydrometric class: the clusters obtained by the unsupervised 3-cluster SOM based on streamflow indexes become, in this second analysis, the predefined reference classification. The goodness of the discriminant analysis is then assessed through the capability of assigning a catchment, on the basis of its morpho-pluviometric attributes only, to the same class to which it would be assigned if its streamflow attributes were known. This approach is similar to that applied by Bhaskar and O'Connor (1989), Chiang et al. (2002) and Sanborn and Bledsoe (2006), albeit with different hydrometric and morpho-climatic sets of indices and different cluster analysis techniques.

\subsection{Principal component analysis of catchment descriptors}

The chosen morphometric and pluviometric catchment descriptors available for ungauged stream-sections (see Sect. 2.3) are a total of $11\left(X, Y, A, H_{\min }, H_{\text {med }}, L, \mu_{P}\right.$, 
Table 2. Morpho-pluviometric variables with the highest loadings on the first three PCs and total explained variance (in parentheses).

\begin{tabular}{lll}
\hline $\mathrm{PC}_{1}(47.8 \%)$ & $\mathrm{PC}_{2}(25.1 \%)$ & $\mathrm{PC}_{3}(16.0 \%)$ \\
\hline$\mu_{P}$ & $A$ & $Y$ \\
$H_{\min }$ & $\rho_{P}(1)$ & $-X$ \\
$\sigma_{P}$ & $L$ & $-\alpha_{P}$ \\
$H_{\text {med }}$ & & \\
$-\alpha_{P},-X$ & & \\
\hline
\end{tabular}

$\left.\sigma_{P}, P_{\mathrm{Wet}}, \rho_{P}(1), \alpha_{P}\right)$. Also due to the above cited overparameterisation constraints, the catchment descriptor vectors are subjected to a principal component analysis to identify a smaller number of uncorrelated variables that describe the dominant patterns of variance in the data.

The principal component analysis shows how the first three principal components (PCs) explain, together, $89 \%$ of the total variance (and the fourth one adds only another $4.6 \%$ of explanation). Table 2 presents the original variables that mostly affect the first three PCs (i.e. those with the highest loadings) and the percentage of total variance explained by each PC.

The principal component analysis helps to interpret the differences and similarities of the data; in fact each PC describes a specific aspect of the variability of the catchment attributes and the variables with the highest loadings on a PC best explain that "dimension" of the data (Chiang et al., 2002; Sanborn and Bledsoe, 2006). The first PC is positively associated with $H_{\mathrm{min}}, H_{\mathrm{med}}, \mu_{P}, \sigma_{P}$, thus representing the influence of elevation, corresponding to higher rainfall values (due to orographic effect), whereas the correlation scaling exponent, $\alpha_{P}$ (and also the $X$ coordinate, since the eastern part of the study region is less markedly rugged and receives less rainfall) contributes with the opposite sign, and therefore with lower values (associated to higher correlation) for increasing altitude. This result is consistent with the findings of Molnar and Burlando (2008), where the most elevated areas exhibit lower $\alpha_{P}$-values (and therefore a stronger correlation, indicating that the orographic forcing leads to better organised and long-lasting precipitation fields). The second PC, associated to $A, L$ and $\rho_{P}(1)$, substantially represents the catchment dimension, increasing along with the lag-1 autocorrelation of the spatially averaged rainfall. The third component, associated with negative $X$ and positive $Y$ values, represents the geographical location; moving along the Apennine ridge from SE to NW, $\alpha_{P}$ decreases. This shows that the precipitation on the Emilia area tends to be more temporally correlated than that on the Romagna area, the latter being less mountainous and less rainy, due also to the influence of the sea and of the southern currents.

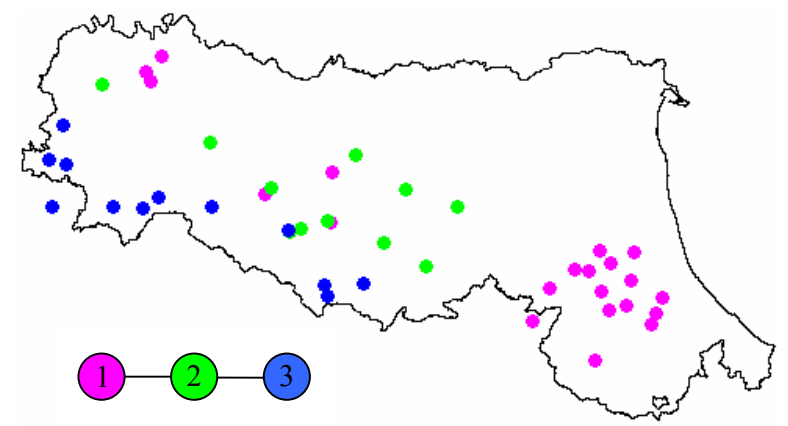

Fig. 6. Classification identified by discriminant analysis based on the first three PCs of the catchment descriptors.

\subsection{Discriminant analysis for classification of ungauged catchments}

Discriminant analysis is a supervised learning technique that treats a set of observations with one classification variable and one or more quantitative variables (or discriminants) to describe each classified entity. On the basis of such information, the algorithm constructs a classification rule as a function of the quantitative variables that allows to assign any new record to one of the predefined groups. The analysis identifies the combination of the quantitative variables that maximises the ratio between the inter-classes variance and the intra-classes variance (thus maximising the inter-class separability and the intra-class compactness of the data samples in a low-dimensional vector space), finding the one that can most effectively partition the predefined groups (Hand, 1981; Krzanowski, 1988).

In the present application, the quantitative variables describing each entity are the first three principal components of the catchment descriptors (presented above) and the classes are the three clusters identified by the SOM network based on the streamflow signatures (see Sect. 3.2). This is consistent with the indications (cited in the same section) that, for an optimal discriminant analysis, it is preferable that the number of discriminant variables multiplied by the number of classes is less than one fourth of the total number of records to be classified (44 in the present case).

The discriminant capacity is assessed through the comparison between the streamflow signatures classification and the one derived by the catchment attributes. It was here performed a leave-one-out cross validation, considering, in turn, each basin as ungauged and therefore excluding it from the data used to construct the discriminant criterion. It is finally possible to determine the percentage of gauged sites correctly classified in the discriminant-based approach. The classification obtained with the discriminant analysis is represented in Fig. 6.

Comparing Figs. 4 and 6, it may be seen that 9 catchments are misclassified (i.e. an error rate around $20 \%$ ): five errors occurred when Class 3 entities were assigned to Class 2 or viceversa; the remaining four errors result from exchanges 
between Class 1 and Class 2. It is worthy observing that there are no instances in which catchments belonging to Class 1 are assigned to Class 3 or the other way round. This is a merit of the topological properties of the SOM network, unique among the other clustering techniques: the relative position of the nodes on the output layer allows, indeed, to take into consideration the affinity among the classes, since nodes that are nearby may be considered representative of akin classes. Classes 1 and 3 correspond, in fact, to the less similar groups, while Class 2 is intermediate between the two. It is hence comforting to observe that the two most different clusters result separately in both classifications and that the only errors are exchanges with the intermediate cluster.

\section{Conclusions}

The methodology developed in this study first provides a means for identifying groups of similar catchments on the basis of streamflow indexes (signatures) and successively classifies, in the same clusters, ungauged basins on the basis of climate and landscape characteristics. The main novelty of the approach lies in the inclusion, both in the streamflow and in the rainfall characterisation, of information derived by the fine-scale continuous time series, through indexes attempting to synthesise, in a parsimonious way, the variability and correlation structure of the respective processes.

The streamflow signatures are fed to two unsupervised self-organising mapping networks, forming respectively 3 and 6 groups of similar catchments, and obtaining - especially for the more refined 6-cluster partition - classes with a clear hydrological distinctiveness. This is highlighted not only by the consistent interpretation of how the main features of the input variables vary in the different classes and of their multi-relations (shown by the topology maps), but also by the spatial distribution of the groups of homogeneous catchments. In fact, even if no geographical, morphological nor climatological information is provided in input to the SOM network, the clusters exhibit an overall consistency as far as location, altitude and precipitation regime are concerned.

On the other hand, as expected, the coarser clustering is not able to fully capture the differences among the hydrometric signatures, and in particular among the dynamic components of the streamflow process: the 3-cluster classification is in fact mainly led by the signatures representing runoff magnitude but it merges basins characterised by very different temporal correlation indexes, indicating that the dynamic component of the process is not given sufficient consideration.

In order to classify new observations (ungauged sites) to an appropriate streamflow response group, a set of morphologic and pluviometric attributes are identified for describing each catchment. The analysis of the principal components (PCs) of the morpho-pluviometric attributes shows that each of the first three PCs seems able to represent a specific aspect of the differences among the catchments, highlighting, in particular, the role and the dependence among the variables characterising the precipitation regime and its correlation structure.

The limited data set prevented the use of the more detailed (6-cluster) classification in the discriminant analysis (applied for assigning ungauged catchments to the predetermined SOM classes based on streamflow signatures), due to over-parameterisation constraints, but it is intended, in future work, to try to enlarge the number of study catchments for allowing also such investigation.

The results of the discriminant analysis, that identifies the membership of ungauged catchments (described by the corresponding three first PCs) in a leave-one-out crossvalidation scheme, evidence a quite satisfactory agreement with the 3-cluster SOM classification that is assumed as a reference partition. Moreover, the discriminant analysis clustering is able to clearly distinguish the two less similar groups (Class 1 and Class 3) identified in the streamflow-based SOM classification: in fact all the misclassification errors are exchanges with the intermediate Class 2.

Of course it is arduous aspiring at a fully appropriate hydrological classification with the set of catchment attributes that are available for this study. For a better characterisation of the phenomena governing the streamflow process, a more comprehensive data set would be needed, including information on the geo-pedological, vegetation and land-use properties of the drainage areas, as well as additional climatic indexes.

In addition, the chosen signatures represent a very simplified description of the autocorrelation function and in particular the assumption of stationarity is indeed a relevant approximation, given the strong seasonality of the streamflow process. It would be worthy, provided that a larger sample of streamflow time series is available, to provide a more refined representation of the correlation structure, in particular for testing the potential advantages of a seasonal interpretation of the data.

Notwithstanding all the above cited limitations, the results confirm the potential of the proposed approach for characterising the catchments. The inclusion of information on the properties of the fine time-scale streamflow and rainfall time series appears a promising way for better delineating the hydrologic and climatic character of the catchments, at least as far as the present study area is concerned.

Acknowledgements. Analyses are based on measurements provided by the Regional Civil Protection Agency and by the Hydro-Meteorological Service of the Environmental Agency of Emilia-Romagna Region. The author also thanks Alberto Viglione and two anonymous reviewers for their constructive comments and helpful suggestions.

Edited by: S. Attinger 


\section{References}

Atkinson, S. E., Woods, R. A., and Sivapalan, M.: Climate, soil, vegetation controls on water balance model complexity over changing timescales, Water Resour. Res., 38, 1314, doi:10.1029/2002WR001487, 2002.

Bhaskar, N. R. and O'Connor, C. A. : Comparison of method of residuals and cluster analysis for flood regionalization, J. Water Resour. Pl.-ASCE, 115, 793-808, 1989.

Burn, D. H.: Cluster analysis as applied to regional floood frequency, J. Water Resour. Pl.-ASCE, 115, 567-582, 1989.

Burn, D. H. and Goel, N. K.: The formation of groups for regional flood frequency analysis, J. Hydrol. Sci., 45, 97-112, 2000.

Burn, D. H., Zrinji, Z., and Kowalchuk, M.: Regionalization of catchments for regional flood frequency analysis, J. Hydrol. Eng., 2, 76-82, 1997.

Castellarin, A., Brath, A., and Burn, D.: Assessing the effectiveness of hydrological similarity measures for flood frequency analysis, J. Hydrol., 241, 270-285, 2001.

Castiglioni, S. Lombardi, L., Toth, E., Castellarin, A. and Montanari, A.: Calibration of rainfall-runoff models in ungauged basins: A regional maximum likelihood approach, Adv. Water Resour., 2010, 33, 1235-1242, 2010.

Chang, F. J., Tsai, M. J., Tsai, W. P., and Herricks, E. E.: Assessing the Ecological Hydrology of Natural Flow Conditions in Taiwan, J. Hydrol., 354, 75-89, 2008.

Chang, F. J., Chang, L. C., Kao, H. S., and Wua, G. R.: Assessing the effort of meteorological variables for evaporation estimation by self-organizing map neural network, J. Hydrol., 384, 118-129, 2010.

Chiang, S. M., Tsay, T. K., and Nix, S. J.: Hydrologic regionalization of watershed. Part I. Methodology development, J. Water Resour. Pl.-ASCE, 128, 1-11, 2002.

Corduas, M.: Clustering streamflow time series for regional classification, J. Hydrol, 407, 73-80, 2011.

De Thomasis, E. and Grimaldi, S.: Introduzione di una metrica tra modelli parametrici lineari nelle applicazioni di tipo idrologico, Giornata di Studio: Metodi Statistici and Matematici per l'Analisi delle Serie Idrologiche, Roma, 2001 (in Italian).

Di Prinzio, M., Castellarin, A., and Toth, E.: Data-driven catchment classification: application to the pub problem, Hydrol. Earth Syst. Sci., 15, 1921-1935, doi:10.5194/hess-15-19212011, 2011.

Grimaldi, S.: Linear parametric models applied to daily hydrological series, J. Hydrol. Eng., 9, 383-391, 2004.

Haines, A. T., Finlayson, B. L., and McMahon, T. A.: A global classification of river regimes, Appl. Geogr., 8, 255-272, 1988.

Hall, M. J. and Minns, A. W.: The classification of hydrological homogeneous regions, J. Hydrol. Sci., 44, 693-704, 1999.

Hall, M. J., Minns, A. W., and Ashrafuzzaman, A. K. M.: The application of data mining techniques for the regionalisation of hydrological variables, Hydrol. Earth Syst. Sci., 6, 685-694, doi:10.5194/hess-6-685-2002, 2002.

Hand, D. J.: Discrimination and Classification, John Wiley and Sons, Inc., New York, 218 pp., 1981.

Hand, D. J.: Construction and Assessment of Classification Rules, Wiley, Chichester, England, 214 pp., 1997.

Herbst, M. and Casper, M. C.: Towards model evaluation and identification using Self-Organizing Maps, Hydrol. Earth Syst. Sci., 12, 657-667, doi:10.5194/hess-12-657-2008, 2008.
Holmes, M. G. R., Young, A. R., Gustard, A., and Grew, R.: A new approach to estimating Mean Flow in the UK, Hydrol. Earth Syst. Sci., 6, 709-720, doi:10.5194/hess-6-709-2002, 2002.

Hosking, J. R. M., Wallis, J. R., and Wood, E. F.: An appraisal of the regional flood frequency procedure in the UK "Flood Studies Report", Hydrolog. Sci. J., 30, 85-109, 1985.

Jingyi, Z. and Hall, M. J.: Regional flood frequency analysis for the Gan-Ming River basin in China, J. Hydrol., 296, 98-117, 2004.

Kohonen, T.: Self-Organizing Maps, 2nd Edn., Springer, 1997.

Krzanowski, W. J.: Principles of Multivariate Analysis, A User's perspective, Oxford Univ. Press, New York, 612 pp., 1988.

Laaha, G. and Bloeschl, G.: A comparison of low flow regionalization methods - catchment grouping, J. Hydrol., 323, 193-214, 2006.

Lettenmeier, D. P., Wallis, J. R., and Wood, E. F.: Effect of regional heterogeneity on flood frequency estimation, Water Resour. Res., 23, 313-323, 1987.

Ley, R., Casper, M. C., Hellebrand, H., and Merz, R.: Catchment classification by runoff behaviour with self-organizing maps (SOM), Hydrol. Earth Syst. Sci., 15, 2947-2962, doi:10.5194/hess-15-2947-2011, 2011.

Lombardi, L., Toth, E., Castellarin, A., Montanari, A., and Brath, A.: Calibration of a rainfall-runoff model at regional scale by optimising river discharge statistics: performance analysis for the average/low flow regime, Phys. Chem. Earth, 42-44, 77-84, 2012.

Marani, M.: On the correlation structure of continuous and discrete point rainfall, Water Resour. Res., 39, 1128, doi:10.1029/2002WR001456, 2003.

McDonnell, J. J. and Woods, R. A.: On the need for catchment classification, J. Hydrol., 299, 2-3, 2004.

Menabde, M., Harris, D., Seed, A., Austin, G., and Stow, D.: Multiscaling properties of rainfall and bounded random cascades, Water Resour. Res., 33, 2823-2830, 1997.

Merz, R. and Bloeschl, G.: Flood frequency regionalization: spatial proximity vs. catchment attributes, J. Hydrol., 302, 283-306, 2005.

Molnar, P. and Burlando P.: Variability in the scale properties of high-resolution precipitation data in the Alpine climate of Switzerland, Water Resour. Res., 44, W10404, doi:10.1029/2007WR006142, 2008.

Montanari, A. and Toth, E.: Calibration of hydrological models in the spectral domain: An opportunity for scarcely gauged basins?, Water Resour. Res., 43, W05434, doi:10.1029/2006WR005184, 2007.

Nathan, R. J. and McMahon, T. A.: Identification of homogeneous regions for the purpose of regionalization, J. Hydrol., 121, 217238, 1990.

Oudin, L., Kay, A., Andreassian, V., and Perrin, C.: Are seemingly physically similar catchments truly hydrologically similar?, Water Resour. Res., 46, W11558, doi:10.1029/2009WR008887, 2010.

Ozger, M., Mishra, A. K., and Signh, V. P.: Seasonal and spatial variations in the scaling and correlation structure of streamflow data, Hydrol. Process., online first, doi:10.1002/hyp.9314, 2012.

Patil, S. and Stieglitz, M.: Hydrologic similarity among catchments under variable flow conditions, Hydrol. Earth Syst. Sci., 15, 989997, doi:10.5194/hess-15-989-2011, 2011. 
Patil, S. and Stieglitz, M.: Controls on hydrologic similarity: role of nearby gauged catchments for prediction at an ungauged catchment, Hydrol. Earth Syst. Sci., 16, 551-562, doi:10.5194/hess16-551-2012, 2012.

Piacentini, T., Castaldini, D., Coratza, P., Farabollini, P., and Miccadei, E.: Geotourism: Some examples in Northern-Central Italy, GeoJournal of Tourism and Geosites, Year IV no. 2, 8, 240-262, 2011.

Samaniego, L., Bardossy, A., and Kumar, R.: Streamflow prediction in ungauged catchments using copula-based dissimilarity measures, Water Resour. Res., 46, W02506, doi:10.1029/2008WR007695, 2010.

Sanborn, S. C. and Bledsoe, B. P.: Predicting streamflow regime metrics for ungauged streams in Colorado, Washington, Oregon, J. Hydrol., 325, 241-261, 2006.

Sauquet, E. and Catalogne, C.: Comparison of catchment grouping methods for flow duration curve estimation at ungauged sites in France, Hydrol. Earth Syst. Sci., 15, 2421-2435, doi:10.5194/hess-15-2421-2011, 2011.

Sawicz, K., Wagener, T., Sivapalan, M., Troch, P. A., and Carrillo, G.: Catchment classification: empirical analysis of hydrologic similarity based on catchment function in the eastern USA, Hydrol. Earth Syst. Sci., 15, 2895-2911, doi:10.5194/hess-15-28952011, 2011.

Singh, R. D., Mishra, S. K., and Chowdhary, H.: Regional flowduration models for large number of ungauged Himalayan catchments for planning microhydro projects, J. Hydrol. Eng., 6, 310316, 2001.
Srinivas, V. V., Tripathi, S., Rao, A. R., and Govindaraju, R. S.: Regional flood frequency analysis by combining self-organizing feature map and fuzzy clustering, J. Hydrol., 348, 148-166, 2008.

Thomas, B., Lischeid, G., Steidl, J., and Dannowski, R.: Regional catchment classification with respect to low flow risk in a Pleistocene landscape, J. Hydrol., 475, 392-402, 2012.

Toth, E.: Classification of hydro-meteorological conditions and multiple artificial neural networks for streamflow forecasting, Hydrol. Earth Syst. Sci., 13, 1555-1566, doi:10.5194/hess-131555-2009, 2009.

Vezza, P., Comoglio, C., Rosso, M., and Viglione, A.: Low Flows Regionalization in North-Western Italy, Water Resour. Manage., 24, 4049-4074, 2010.

Viglione, A., Claps, P., and Laio, F.: Mean Annual Runoff Estimation in North-Western Italy, in: Water resources assessment and management under water scarcity scenarios, edited by: La Loggia, G., CDSU Publ. Milano, Italy, 2006.

Wagener, T., Sivapalan, M., Troch, P., and Woods, R.: Catchment Classification and Hydrologic Similarity, Geogr. Compass, 1, 901-931, doi:10.1111/j.1749-8198.2007.00039.x, 2007.

Yilmaz, K. K., Gupta, H. V., and Wagener, T.: A process based diagnostic approach to model evaluation: Application to the NWS distributed hydrologic model, Water Resour. Res., 44, W09417, doi:10.1029/2007WR006716, 2008. 